ISSN 0103-9954

\title{
FUNGOS MICORRÍZICOS ARBUSCULARES EM SOLOS DA RESERVA BIOLÓGICA MUNICIPAL SERRA DOS TOLEDOS, ITAJUBÁ/MG
}

\author{
ARBUSCULAR MICORRHIZAL FUNGI IN SOILS FROM MUNICIPAL BIOLOGICAL \\ RESERVE SERRA DOS TOLEDOS, ITAJUBÁ/MG
}

\author{
Rogério Melloni ${ }^{1}$ Elisa da Costa Guida ${ }^{2}$ \\ Marielle Rezende de Andrade ${ }^{2}$ Eliane Guimarães Pereira Melloni ${ }^{3}$
}

\begin{abstract}
RESUMO
A Reserva Biológica Municipal Serra dos Toledos é um importante remanescente de Mata Atlântica no sul de Minas Gerais, com elevada biodiversidade e riqueza em recursos hídricos. Estudos relacionados à qualidade de solos são necessários em planos de manejo de reservas, os quais objetivam manter ou melhorar a sustentabilidade ambiental dessas áreas. Assim, o objetivo do presente trabalho foi avaliar o potencial de inóculo de fungos micorrízicos arbusculares (MAs) em amostras de solo características desta Reserva. A quantificação de propágulos desse grupo de micro-organismos, que estabelecem simbiose mutualística com a maioria das espécies vegetais é importante para a avaliação da qualidade de solos da Reserva. Foram definidas três áreas internas e uma externa à Reserva, retirando-se amostras de solo na profundidade de 0 a $10 \mathrm{~cm}$, em duas épocas, inverno de 2008 e verão de 2009. As amostras foram encaminhadas ao Laboratório de Microbiologia da Universidade Federal de Itajubá para quantificação dos seguintes atributos microbiológicos relacionados aos fungos MAs: comprimentos de micélio extrarradicular ativo e total pelo método da fluorescência induzida com diacetato de fluoresceína, densidade e diversidade fenotípica (morfotipos) de esporos, porcentagem e intensidade de colonização radicular. As médias dos resultados foram comparadas por Duncan 5\% e submetidas à análise de multivariada. Os resultados mostraram que o potencial de inóculo de fungos MAs apresentou maior efeito das áreas que das épocas estudadas, sendo maior comprimento de micélio extrarradicular ativo e total, maior proporção de micélio ativo em relação ao total e maior diversidade de esporos obtidos nos solos dentro da Reserva Biológica Municipal Serra dos Toledos, em relação ao solo externo à mesma, sob pastagem. O potencial de inóculo não está diretamente relacionado à fertilidade do solo, ou seja, no solo externo à Reserva, sob pastagem, apesar da melhor fertilidade, foram encontrados os menores valores de micélio e diversidade de esporos de fungos MAs.
\end{abstract}

Palavras-chave: micorriza; micélio extrarradicular; esporos.

\begin{abstract}
The City Biological Reserve of 'Serra dos Toledos' is an important remaining tropical rain forest in south Minas Gerais statewhich has high biodiversity and water resources. Studies related to soil quality are needed in the reserve management plans, which aim to maintain or to improve the environmental sustainability of these areas. Thus, the purpose of this work was to evaluate the inoculum potential of arbuscular mycorrhizal fungi (AM) in samples of typical soil of that reserve. The quantifcation of propagules of this microbial group that establishes mutualistic symbiosis with most plant species, it is important for assessing the soil quality of the reserve. Three areas inside and one outside the Reserve were set to study, where soil samples were removed at depth 0 to $10 \mathrm{~cm}$, in two seasons, winter 2008 and summer 2009. The samples were sent to the Laboratory of Microbiology of the University of 'Itajubá' for quantification of the following
\end{abstract}

1. Engenheiro agrônomo, Dr., Professor Associado da Universidade Federal de Itajubá, Av. BPS, 1303, Bairro Pinheirinho, Caixa Postal 50, CEP 37500-903, Itajubá (MG).rmelloni@unifei.edu.br

2. Engenheira Ambiental, Universida de Federal de Itajubá, Av. BPS, 1303, Bairro Pinheirinho, Caixa Postal 50, CEP 37500-903, Itajubá (MG). Ex-bolsista de Iniciação Científica, do CNPq. elisaeam@gmail.com / mareleandrade@hotmail.com

3. Engenheira agrônoma, Drª ${ }^{\mathrm{a}}$, Professora Adjunta da Universidade Federal de Itajubá, Av. BPS, 1303, Bairro Pinheirinho, Caixa Postal 50, CEP 37500-903, Itajubá (MG). elianegp@unifei.edu.br

Recebido para publicação em 11/05/2010 e aceito em 27/07/2010 
microbiological attributes related to AM fungi: lengths of total and active extra-radical mycelium by the method of induced fluorescence with fluorescein diacetate, density and phenotypic diversity (morphotypes) of spores, percentage and intensity of root colonization. The average results were compared by Duncan 5\% and subjected to multivariate analysis. The results showed that the potential for MA fungal inoculum had a higher effect of areas in relation to the studied periods, with greater length of active and total extra-radical mycelium, a higher proportion of active mycelium in relation to the total and a greater diversity of spores in soil from the City Biological Reserve of 'Serra dos Toledos', compared to the outside soil under pasture. The inoculum potential is not directly related to the soil fertility, where that outside the reserve, pasture, despite the best fertility were found smaller values of mycelium and diversity of MA fungal spores.

Keywords: micorhiza; extra-radical mycelium; spores.

\section{INTRODUÇÃO}

A Reserva Biológica Municipal Serra dos Toledos é uma unidade de conservação criada pela Lei 1.211 de 05/06/1979, na Área de Proteção Ambiental da Mantiqueira, em ItajubáMG. Segundo dados da Prefeitura Municipal de Itajubá (2002), possui 1.072 hectares de vegetação de Mata Atlântica primária e principalmente secundária, abrigando, além da riqueza em recursos hídricos, grande diversidade de espécies da fauna e flora endêmica, como perobas (Aspidosperma parvifolium A.CD.), angicos (Parapiptadenia rígida (Benth.) Brenan), jacarandás (Jacaranda mimosifolia D. Don), cedro (Cedrela fissilis Vell.), jequitibá (Cariniana estrellensis (Raddi) Kuntze), cajarana (Spondias dulcis Forst. F.), candeia (Arisarum vulgare Targ.-Tozz.), canelas (Nectandra lanceolata Nees et Mart.), araucárias (Araucaria angustifólia (Bert.) O. Kuntze) e grande variedade de bromélias (Vriesea sp) e orquídeas (Dendrobium sp). A cobertura vegetal original é representada pelo contato Floresta Ombrófila Densa/Floresta Ombrófila Mista, também conhecida como Mata de Araucárias ou Pinheiral, sendo assim uma Área de Tensão Ecológica (área onde ocorre o contato entre duas regiões fitoecológicas) sob a forma de encrave, onde cada formação guarda sua identidade ecológica sem se misturar (BRASIL, 1983).

A ação antrópica exercida na Reserva ameaça a qualidade ambiental de solos e vegetação. Um dos métodos para se avaliar a qualidade do solo é pela diversidade funcional ou funcionalidade de grupos microbianos específicos. A atividade de micro-organismos como fungos micorrízicos arbusculares (MAs) apresenta grande potencial de utilização como bioindicador da qualidade do solo (TURCO et al., 1994; MELLONI et al., 2003), principalmente pela participação nos diferentes ciclos biogeoquímicos, pelo aumento da disponibilidade de nutrientes às plantas (PEREIRA et al., 1996 a,b), por proporcionar maior tolerância a estresses abióticos ligados à variação de temperatura e umidade (JOHNSON e PFLEGER, 1992; SMITH e READ, 1997), pela contribuição ao processo de agregação do solo e, consequentemente à sustentabilidade do ambiente (SIQUEIRA et al., 1994; SMITH e READ, 1997). Estes microorganismos apresentam sensibilidade a atividades antropogênicas, além de altas correlações com funções benéficas do solo diretamente relacionadas a atributos físicos, químicos e microbiológicos da qualidade do solo (KLING e JAKOBSEN, 1998; ALVARENGA et al., 1999; DORAN e ZEISS, 2000).

A diversidade dos fungos MAs está relacionada com a diversidade da vegetação (HEIJDEN et al., 1998), sendo, portanto, de grande importância à estruturação, ao desenvolvimento e à sustentabilidade da comunidade vegetal em ecossistemas como os da Reserva Biológica Municipal Serra dos Toledos. Portanto, atividade antropogênica relacionada à fertilização, ao revolvimento ou à retirada da cobertura vegetal pode provocar a quebra da rede micelial (KABIR et al., 1997; MELLONI et al., 2003) e comprometer sua agregação, absorção e transporte de água e nutrientes pelos diferentes hospedeiros. A sua quantificação, independentemente da metodologia utilizada, deve ser considerada em planos de manejo de solos e plantas da Reserva, principalmente em função da sua sensibilidade em indicar impactos advindos de sua utilização.

Portanto, conhecendo a importância do grupo microbiano no desenvolvimento vegetal e funcionamento de ecossistemas como o da Reserva Biológica Municipal Serra dos Toledos, o principal objetivo do presente estudo foi avaliar o potencial de inóculo de fungos micorrízicos arbusculares em amostras de solos característicos da Reserva, 
de modo a fornecer informações para a elaboração do seu plano de manejo e, consequentemente, da sustentabilidade do desenvolvimento das espécies vegetais atualmente presentes.

\section{MATERIAL E MÉTODOS}

Baseados nos dados pedológicos levantados por Pereira (2007) na Reserva Biológica Municipal Serra dos Toledos, em Itajubá-MG, foram selecionadas três áreas em diferentes declividades e solos característicos: a) área plana (P) com relevo suave a suave ondulado, $12,96 \%$ de declive e coordenadas geográficas de $22^{\circ} 25^{\prime} 48,8^{\prime \prime} \mathrm{S}$ e $45^{\circ} 22^{\prime} 18,3^{\prime \prime} \mathrm{W}$, em Latossolo Vermelho Distrófico Típico - LVd; b) área mediana (M) com relevo ondulado, declive de $35,34 \%$ e coordenadas geográficas de $22^{\circ} 25^{\prime} 33,3^{\prime \prime} \mathrm{S}$ e $45^{\circ} 22^{\prime} 20,9^{\prime \prime} \mathrm{W}$, em Latossolo Vermelho Distrófico Típico - LVd; c) área inclinada (I) com relevo montanhoso, $56,09 \%$ de declive e coordenadas geográficas de $22^{\circ} 25^{\prime} 45,5^{\prime \prime} \mathrm{S}$ e $45^{\circ} 22^{\prime} 17,0^{\prime \prime} \mathrm{W}$, em Argissolo VermelhoAmarelo Alumínico - PVAa. Uma quarta área sob pastagem, na zona de amortecimento da Reserva, foi também selecionada, a qual apresenta média à baixa declividade e coordenadas geográficas de $22^{\circ} 25^{\prime} 28,2^{\prime \prime}$ S e $45^{\circ} 22^{\prime} 15,0^{\prime \prime} \mathrm{W}$.

Para as coletas de amostras de solo visando caracterização microbiológica, cada área foi dividida em cinco subáreas, obtendo-se cinco amostras compostas, formadas por cinco subamostras cada. As subamostras foram retiradas por meio de enxada, em zigue-zague, na profundidade de 0 a $10 \mathrm{~cm}$, desinfestando-a com álcool $70 \%$ a cada amostragem. Essas coletas foram realizadas em duas estações climáticas, no inverno de 2008 e verão de 2009 , a fim de se verificar a sensibilidade e capacidade de discriminação das diferentes áreas por meio dos atributos microbiológicos. As amostras de solo foram acondicionadas em sacos plásticos e encaminhadas ao Laboratório de Microbiologia, da UNIFEI, peneiradas em malha de $2 \mathrm{~mm}$ e mantidas a $4^{\circ} \mathrm{C}$ até a avaliação dos atributos de interesse.

Das amostras de solo coletadas, foram determinados os comprimentos de micélio extrarradicular ativo e total de fungos do solo pelo método da fluorescência induzida com diacetato de fluoresceína - FDA (MELLONI e CARDOSO, 1999), sendo o micélio extrarradicular ativo facilmente observado pela fluorescência em microscópio de epifluorescência equipado com luz ultravioleta.
Adensidade total de esporos foi determinada após separação por peneiramento úmido, (GERDEMANN e NICOLSON, 1963). Os esporos foram separados em função de características fenotípicas como cor, tamanho e forma, compondo os diferentes morfotipos, antes da identificação. Pela distribuição nos morfotipos, calculou-se a riqueza das espécies por meio do índice de diversidade de Shannon e Weaver (1949).

Porções de raízes presentes nas amostras de solo de cada área foram reunidas, clarificadas e coradas (PHILLIPS e HAYMAN, 1970) para avaliação da colonização micorrízica, estimada pelo método da placa quadriculada (GIOVANETTI e MOSSE, 1980). Outros segmentos de raízes de aproximadamente $1 \mathrm{~cm}$ foram clarificados e corados pela mesma metodologia anterior, mas avaliados em lâminas de microscopia, obtendo-se a intensidade de colonização radicular. Atribuíramse notas de 0 a 100 , conforme a ocupação da área radicular pelas estruturas fúngicas observadas sob microscópio óptico no aumento real de 100 vezes (BETHLENFALVAY et al., 1981).

Todas as amostras de solo foram ainda caracterizadas por atributos químicos. Para isso, as amostras coletadas foram secas em estufa $\left(65^{\circ} \mathrm{C}\right)$ até peso constante e peneiradas em malha de $2 \mathrm{~mm}$, sendo então analisados: $\mathrm{pH}$ em água na relação 1:2,5; $\mathrm{Ca}, \mathrm{Mg}$ e Al trocáveis extraídos com $\mathrm{KCl} 1 \mathrm{~mol} \mathrm{~L}^{-1}$, analisados por titulometria; $\mathrm{P}$ e $\mathrm{K}$ extraídos pelo método Mehlich 1 e determinados por colorimetria e fotometria de chama, respectivamente; $\mathrm{S}$ por turbidimetria. A matéria orgânica foi avaliada por colorimetria, utilizando-se o método Walkley \& Black. Os métodos encontram-se descritos em Embrapa (1997), sendo os resultados apresentados na Tabela 1.

Todos os resultados foram submetidos à análise de variância pelo teste $\mathrm{F}$, com comparação de médias por Duncan a 5\% de significância por meio do programa Sanest (ZONTA et al., 1984). Foram necessárias transformações para normalização das variâncias: a intensidade de colonização radicular e porcentagem de colonização radicular foram submetidas à transformação $\operatorname{arcseno}(\mathrm{x} / 100)$ e a densidade total de esporos à transformação $\sqrt{(x+0)}$. Os valores médios dos atributos químicos e microbiológicos obtidos das amostras de solo das diferentes áreas de estudo foram utilizados para análise de componentes principais (PCA) por meio do programa PC-ORD 3.12 (McCUNE e MEFFORD, 1997). 
TABELA 1: Atributos químicos das amostras de solo das diferentes áreas de estudo, coletadas no inverno de 2008 e verão de 2009.

TABLE 1: Chemical attributes of soil samples collected from different areas, in winter 2008 and summer 2009.

\begin{tabular}{|c|c|c|c|c|c|c|c|c|c|c|c|c|c|c|}
\hline \multirow[t]{2}{*}{ Áreas } & $\mathrm{pH}$ & $\mathrm{P}$ & $\mathrm{K}$ & $\mathrm{Ca}^{2+}$ & $\mathrm{Mg}^{2+}$ & $\mathrm{Al}^{3+}$ & $\mathrm{H}+\mathrm{Al}$ & $\mathrm{SB}$ & $(\mathrm{t})$ & $(\mathrm{T})$ & & $\mathrm{m}$ & MO & P-rem \\
\hline & $\mathrm{H}_{2} \mathrm{O}$ & \multicolumn{2}{|c|}{$\mathrm{mg} \mathrm{dm}{ }^{-3}$} & \multicolumn{7}{|c|}{ - } & \multicolumn{2}{|c|}{$\%$} & dag $\mathrm{kg}^{-1}$ & $\mathrm{mg} \mathrm{L}^{-1}$ \\
\hline \multicolumn{15}{|c|}{ Inverno/2008 } \\
\hline Plana & 5,0 & 7,5 & 81,0 & 1,7 & 0,9 & 0,8 & 7,9 & 2,8 & 3,6 & 10,7 & 26,2 & 22,0 & 4,0 & 31,0 \\
\hline Média & 4,7 & 6,2 & 111,0 & 1,5 & 0,8 & 1,0 & 8,8 & 2,6 & 3,6 & 11,4 & 22,7 & 28,0 & 2,7 & 21,7 \\
\hline Inclinada & 5,1 & 3,7 & 66,0 & 2,7 & 0,7 & 0,3 & 5,0 & 3,6 & 3,9 & 8,6 & 41,7 & 8,0 & 5,6 & 30,0 \\
\hline Externa & 6,0 & 5,5 & 309,0 & 10,5 & 3,9 & 0,1 & 2,6 & 15,2 & 15,3 & 17,8 & 85,4 & 1,0 & 4,4 & 34,1 \\
\hline \multicolumn{15}{|c|}{ Verão/2009 } \\
\hline Plana & 5,2 & 4,9 & 87,0 & 3,4 & 1,6 & 0,4 & 7,0 & 5,2 & 5,6 & 12,2 & 42,7 & 7,0 & 3,4 & 35,2 \\
\hline Média & 4,7 & 2,8 & 69,0 & 0,7 & 0,5 & 1,2 & 7,9 & 1,4 & 2,6 & 9,3 & 14,9 & 47,0 & 4,8 & 30,7 \\
\hline Inclinada & 5,7 & 3,1 & 59,0 & 2,2 & 0,8 & 0,2 & 3,6 & 3,2 & 3,4 & 6,8 & 46,7 & 6,0 & 2,2 & 38,6 \\
\hline Externa & 6,5 & 6,8 & 234,0 & 12,9 & 1,8 & 0,0 & 1,5 & 15,3 & 15,3 & 16,8 & 91,1 & 0,0 & 2,5 & 37,5 \\
\hline
\end{tabular}

Em que: $\mathrm{SB}=$ soma de bases; $\mathrm{t}=$ capacidade de troca catiônica efetiva; $\mathrm{T}=$ capacidade de troca catiônica em $\mathrm{pH} 7$; $\mathrm{V}=$ saturação por bases; $\mathrm{m}$ = saturação por Alumínio; e $\mathrm{MO}=$ teor de matéria orgânica

\section{RESULTADOS E DISCUSSÃO}

Emgeral, houvealteraçãono comportamento de micélio extrarradicular ativo (MEA) e total (MET) nas diferentes áreas e épocas de amostragem, com maiores valores nas áreas de dentro da Reserva (Tabela 2). Os menores valores para a área externa da Reserva (zona de amortecimento) podem estar relacionados às diferenças físicas, químicas e biológicas da rizosfera amostrada (SMITH e READ, 1997), à substituição da cobertura vegetal por pastagem, podendo ter acarretado a quebra da rede micelial desses fungos (MELLONI et al., 2003). A vegetação da área externa é caracterizada por espécies de baixo porte, na maioria gramíneas, havendo diferença na morfologia das raízes em relação às plantas de dentro da Reserva. Este é um fator relevante na comparação das áreas devido ao grau de compatibilidade fungo/planta/hospedeiro de diferentes espécies (MOREIRA e SIQUEIRA, 2006). Os valores de micélio foram semelhantes aos obtidos por Cardoso Filho et al. (1999), Melloni et al. (2000) e Nogueira e Cardoso (2000), apesar desses terem sido obtidos em experimentos sob condições controladas em casa de vegetação.

No verão, normalmente se observam melhores condições para desenvolvimento radicular e isso é mais intenso em condições naturais, quando há um aumento da mineralização de matéria orgânica e disponibilização de nutrientes às plantas e microorganismos (MOREIRA e SIQUEIRA, 2006). Com isso, as colonizações intra e extrarradicular podem ser influenciadas e, até mesmo, inibidas, impactando negativamente as estruturas fúngicas como o micélio extrarradicular. Além desse efeito, deve-se ainda considerar a utilização das hifas fúngicas como fonte de carbono e energia por outros organismos do solo, também favorecidos pelas melhores condições de solo no verão, reduzindo os comprimentos de micélio do inverno para o verão (Tabela 2).

Outro aspecto importante se refere à elevada proporção de MEA com relação ao MET apresentada nas amostras de verão, revelando que, apesar de valores relativamente menores de MET, a parte ativa dos micélios apresentou geralmente comprimentos maiores em relação aos do inverno. O MEA interfere na maior absorção de água e nutrientes pelas plantas (SYLVIA, 1992), muito 
TABELA 2: Micélio extrarradicular ativo (MEA) e total (MET), intensidade (IC) e porcentagem de colonização micorrízica (PC), densidade de esporos (DE) e índice de diversidade $\left(\mathrm{H}^{\prime}\right)$ de fungos micorrízicos arbusculares, nas duas épocas de amostragem de solo, nas diferentes áreas de estudo na Reserva Biológica Municipal Serra dos Toledos.

TABLE 2: Active (MEA) and total (MET) extra-radical mycelium, intensity (IC) and percent of mycorrhizal colonization (PC), density of spores (DE) and diversity index $\left(\mathrm{H}^{\prime}\right)$ of arbuscular mycorrhizal fungi, in the sampling times from different areas, in the City Biological Reserve of 'Serra dos Toledos'.

\begin{tabular}{|c|c|c|c|c|c|c|c|}
\hline \multirow[t]{2}{*}{ Áreas } & MEA & MET & Proporção MEA/MET & IC & $\mathrm{PC}$ & $\mathrm{DE}$ & $\mathrm{H}^{\prime}$ \\
\hline & $\mathrm{m} \mathrm{g}^{-1} \mathrm{~s}$ & seco & $\%$ & \multicolumn{2}{|c|}{$\%$} & $\mathrm{n}^{\mathrm{o}} 50 \mathrm{~g}^{-1}$ solo & \\
\hline & \multicolumn{7}{|c|}{ Inverno/2008 } \\
\hline Plana & $1,19 \mathrm{a}$ & $7,97 \mathrm{a}$ & 14,9 & $7,91 \mathrm{c}$ & $31,40 \mathrm{~d}$ & $28 b$ & 1,54 \\
\hline Média & $0,48 b$ & $8,41 \mathrm{a}$ & 5,7 & $23,06 \mathrm{~b}$ & $38,05 \mathrm{c}$ & $35 b$ & 1,57 \\
\hline Inclinada & $0,47 b$ & $8,02 \mathrm{a}$ & 5,9 & $39,93 \mathrm{ab}$ & $50,55 \mathrm{~b}$ & $68 \mathrm{a}$ & 1,29 \\
\hline Externa & $0,33 b$ & $3,25 b$ & 10,1 & $49,20 \mathrm{a}$ & $62,90 \mathrm{a}$ & $97 \mathrm{a}$ & 0,82 \\
\hline \multirow[t]{2}{*}{ CV $(\%)$} & 53,5 & 22,3 & - & 25,8 & 5,8 & 16,5 & - \\
\hline & \multicolumn{7}{|c|}{ Verão/2009 } \\
\hline Plana & $1,07 \mathrm{a}$ & $4,66 \mathrm{a}$ & 23,0 & $10,04 \mathrm{~b}$ & $31,75 \mathrm{c}$ & $23 b$ & 1,71 \\
\hline Média & $1,32 \mathrm{a}$ & $4,35 \mathrm{a}$ & 30,3 & $24,35 \mathrm{ab}$ & $56,23 \mathrm{~b}$ & $39 a$ & 1,68 \\
\hline Inclinada & $0,41 b$ & $2,98 \mathrm{a}$ & 13,7 & $19,03 \mathrm{ab}$ & $52,94 \mathrm{~b}$ & $38 \mathrm{a}$ & 1,63 \\
\hline Externa & $0,30 \mathrm{~b}$ & $3,25 \mathrm{a}$ & 9,2 & $28,33 \mathrm{a}$ & $63,61 \mathrm{a}$ & $48 \mathrm{a}$ & 1,40 \\
\hline CV $(\%)$ & 36,5 & 30,9 & - & 33,8 & 7,0 & 15,4 & - \\
\hline
\end{tabular}

Em que: Médias seguidas por letras iguais, nas áreas, não diferem estatisticamente entre si, a 5\% de significância, por Duncan, dentro de cada época de amostragem.

importante na época de verão, onde o crescimento vegetal é mais intenso e rápido, principalmente dentro da Reserva em estudo.

Com relação à colonização micorrízica, observa-se que houve efeito entre as áreas de estudo tanto para intensidade (IC) quanto para porcentagem (PC) de colonização micorrízica. Os valores obtidos para IC e PC foram relativamente maiores para o segundo atributo, apresentaram mesmos comportamentos de distribuição em relação às áreas de estudo, com maiores valores para aquela localizada fora da Reserva. Esta diferença observada entre esses atributos está relacionada ao fato do primeiro (IC) estar ligado ao volume radicular ocupado por propágulos fúngicos, enquanto o segundo (PC) à simples ocorrência dos propágulos nas raízes. Esse resultado pode significar que o estabelecimento e funcionamento da simbiose é dependente da compatibilidade entre as entidades ou dependência do(s) hospedeiro(s) em relação ao fungo, variável em função das condições edáficas geradas nas diferentes áreas. Segundo Poggiani e Schumacher (2000), em ecossistemas naturais, como florestas, a ciclagem de nutrientes pode ser mais intensa e, consequentemente, o estímulo para ocorrência das interações micorrízicas com seus hospedeiros pode ser reduzido, com impacto negativo na sua colonização radicular. Por outro lado, em áreas cultivadas e expostas a processos erosivos, como é o caso da pastagem (área externa da Reserva), o inverso é válido, ou seja, a presença dos fungos MAs pode ser determinante e fundamental para o desenvolvimento das espécies vegetais submetidas a estresses diversos, como inverno 
seco, queimadas eventuais e solos ácidos, de baixa fertilidade natural, característicos da região.

Para densidade de esporos, houve efeito entre as áreas, com os menores valores principalmente na área plana da Reserva e os maiores nas demais áreas, incluindo a externa da mesma, em ambas as épocas de amostragem. Melloni et al. (2001), avaliando características biológicas de solos sob mata ciliar e campo cerrado, observaram maior número de esporos no primeiro ecossistema, sendo de 30 e 10 esporos por 20 gramas de solo, respectivamente. $\mathrm{O}$ maior número de esporos em solo de mata naquele estudo pode estar relacionado à maior diversidade vegetal, possivelmente com predominância de espécies micotróficas e com condições edáficas mais propícias à esporulação. Siqueira et al. (1994) comentaram que uma acelerada imobilização de nutrientes pelos micro-organismos pode auxiliar a formação de simbioses radiculares, como micorriza, que facilitam a aquisição de nutrientes, principalmente em ambientes pobres como os estudados. No atual estudo, mesmo em solo sob pastagem, a densidade de esporos foi elevada, em ambas as amostragens, principalmente no inverno. Condições climáticas mais secas (média de precipitação mensal de $27 \mathrm{~mm}$ ) e frias do inverno (média de $16^{\circ} \mathrm{C}$ ), comparadas às médias do verão (290 $\mathrm{mm} \mathrm{e} 22^{\circ} \mathrm{C}$, respectivamente), conforme dados do CPTEC (2010), podem ter ocasionado situação de estresse mais elevado nessa área externa, o que promoveu maior esporulação de fungos MAs (MOREIRA e SIQUEIRA, 2006).

A variação da esporulação pode ainda estar relacionada às diferenças de fertilidade entre os solos do inverno e verão (Tabela 1), em que se observam menores valores dos atributos $\mathrm{K}, \mathrm{Ca}^{2+}$, $\mathrm{Mg}^{2+}, \mathrm{Al}^{3+}$, soma de bases trocáveis, capacidade de troca catiônica efetiva, capacidade de troca catiônica a pH 7,0, índice de saturação de bases, índice de saturação de alumínio, matéria orgânica, oxidação e fósforo remanescente em todas as áreas de estudo no período de inverno. Esses valores podem estar associados às condições climáticas desfavoráveis ao processo de mineralização da matéria orgânica (BAYER e MIELNICZUK, 2008). A redução de certos atributos químicos no inverno foi também estudada por Costa (2005), o qual verificou, entre outros, a diminuição do teor de fósforo em solos de pastagem nessa estação do ano. Esta condição de menor fertilidade pode influenciar a relação planta/fungo e alterar positivamente a densidade dos esporos, como de fato ocorreu na área externa à

\section{Reserva.}

No total, foram obtidos sete morfotipos de fungos, separados conforme a forma, tamanho e cor, sob microscópio estereoscópico e denominados de A a G. Geralmente, o número médio de esporos por morfotipo foi maior no inverno que no verão, em todas as áreas de estudo, com domínio dos morfotipos A, B e C em detrimento do D (nas amostras de inverno), E, F e $\mathrm{G}$ (nas amostras de verão). O domínio de morfotipos em diferentes ambientes pode ser resultado da preferência por hospedeiros presentes nas áreas ou maior resistência em relação às condições ambientais (clima, condições edáficas, etc.), principalmente estressantes, instaladas nas mesmas. Exemplo é a área externa da Reserva (pastagem), a qual apresentou domínio do morfotipo A (Figura 1) e, com isso, menor diversidade (Tabela 2). Nessa, apenas os morfotipos mais resistentes conseguem sobreviver, uma vez que, para germinarem, os esporos usam suas próprias reservas, que são mobilizadas pelo metabolismo catabólico (MOREIRA e SIQUEIRA, 2006) e depois dependem somente da planta hospedeira para obtenção de energia (biotrofismo obrigatório). Pelo índice de diversidade de Shannon-Weaver (H') verifica-se que houve tendência de maior diversidade fenotípica de esporos de fungos MAs nas áreas internas da Reserva, principalmente no inverno. Este resultado mostra a riqueza microbiológica dos solos da Reserva em relação à área externa, de pasto, a qual apresentou domínio de morfotipos como o A (Tabela 2, Figura 1).

Ainda, nessa área externa à Reserva, em virtude da menor diversidade vegetal ou homogeneidade da rizosfera, pode ter havido menor estímuloà formaçãodemicorriza(RAMOS-ZAPATA e GUADARRAMA, 2004) ou homogeneidade da rizosfera, direcionando a esporulação de alguns morfotipos. Kiriachek et al. (2009) destacam o papel dos hospedeiros na simbiose, salientando que as plantas secretam substâncias que estimulam a germinação de esporos e o crescimento de fungos MAs, com evidências de que os mesmos sintetizam moléculas sinalizadoras, reconhecidas pelas plantas hospedeiras. Ainda, a importância do hospedeiro na formação de associação micorrízica foi discutida por Pouyou-Rojas et al. (2006), os quais verificaram, por análise da compatibilidade fungo/hospedeiro e comportamento geral das espécies em associação, a ocorrência de seletividade diferenciada na relação fungo/hospedeiro, com eficiência simbiótica muito variável entre as plantas hospedeiras estudadas.

Ci. Fl., v. 21, n. 4, out.-dez., 2011 


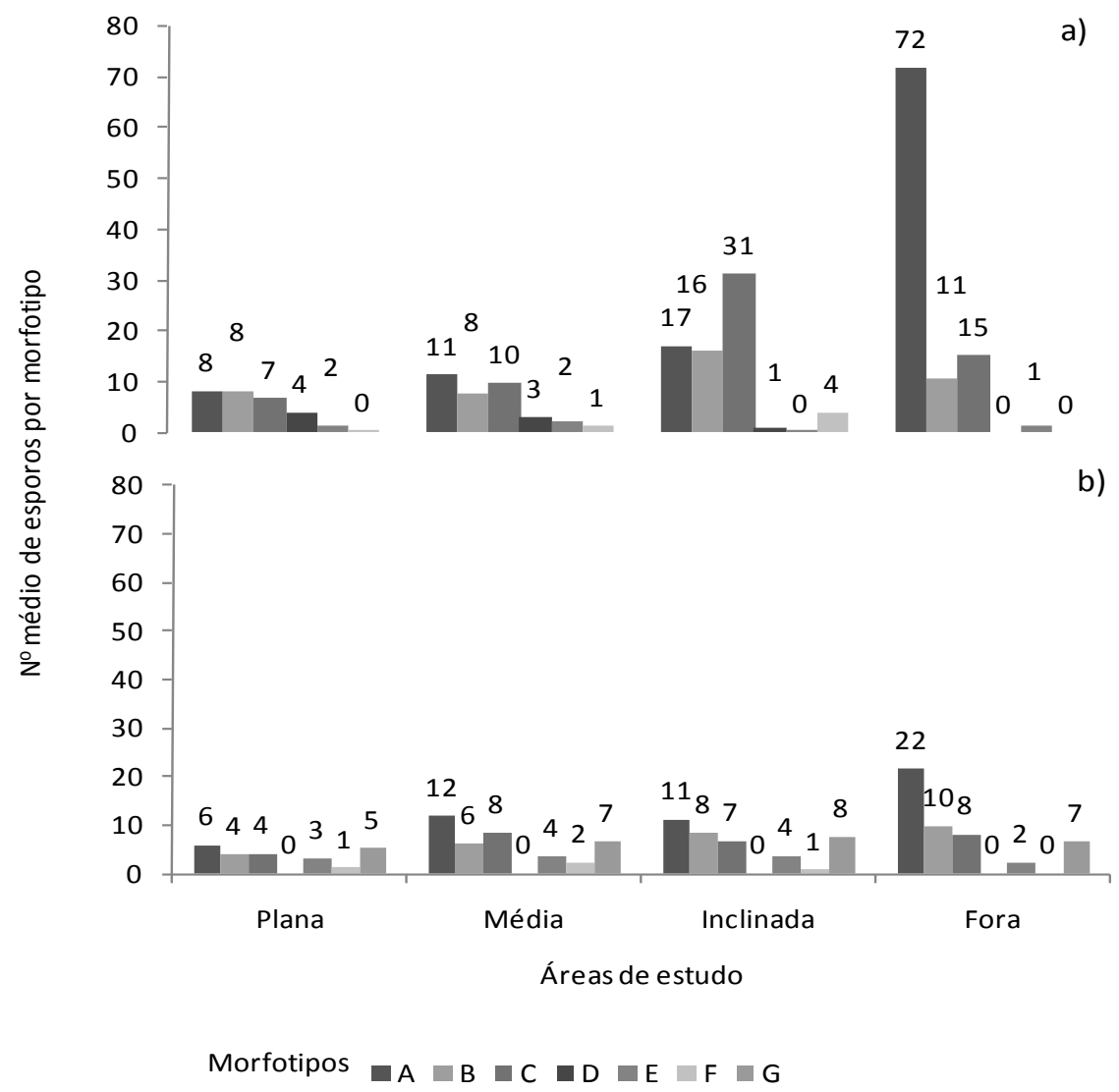

FIGURA 1: Número médio de esporos por morfotipo nas áreas de estudo e épocas de amostragem de solo, inverno de 2008 (a) e verão de 2009 (b).

FIGURE 1: Average number of spores from arbuscular mycorrhizal fungi divided by morphotypes in different areas and sampling times, in winter 2008 (a) and summer 2009 (b).

Paralelamente, em solos internos da Reserva, devido à maior diversidade vegetal e, consequentemente, maior diferenciação da rizosfera, estímulos diferenciados podem ter ocorrido à formação de micorriza e maior diversidade de fungos MAs, contribuindo diretamente à maior sustentabilidade desses ecossistemas.

Os componentes principais ( $\mathrm{PC} 1$ e $\mathrm{PC} 2$ ) compuseram $91,5 \%$ e $89,6 \%$ da variância total dos dados, sendo que o PC1 apresentou 76,3\% e $59,9 \%$ da variância total e o PC2 $15,2 \%$ e $29,8 \%$, respectivamente para inverno (Figura $2 \mathrm{a}$ ) e verão (Figura 2b). Em vista desses altos valores, somente esses dois PCs foram apresentados. Diferentemente do observado por meio de comparação de médias por Duncan (Tabela 2), onde houve variação do comportamento dos atributos estudados em função das áreas e épocas de amostragem, pela análise multivariada praticamente não houve variação na distribuição das áreas nos eixos em função das épocas de amostragem. Destacam-se a separação da área externa (pastagem) das demais em função dos melhores valores dos atributos químicos, e a manutenção do comportamento dos atributos densidade de esporos (DE) e colonização radicular (IC e PC) nessa área, com valores significativamente superiores aos observados nas demais áreas de dentro da Reserva.

As áreas plana e média mantiveramse semelhantes quanto aos atributos analisados, destacando-se os maiores valores de MEA e MET, apesar das piores condições de fertilidade. Baixa fertilidade natural foi também observada por Miranda et al. (2007), na Reserva Biológica União, RJ, a qual limitou o processo de humificação e liberação de nutrientes. No entanto, assim como pode ter ocorrido nos solos estudados, o material humificado isolado da Mata Atlântica apresentou maior intensidade de fluorescência, sugerindo maior labilidade e disponibilidade de nutrientes às plantas. Alvarenga et al. (1999) e Melloni et al. (2008), corroborando os resultados encontrados 

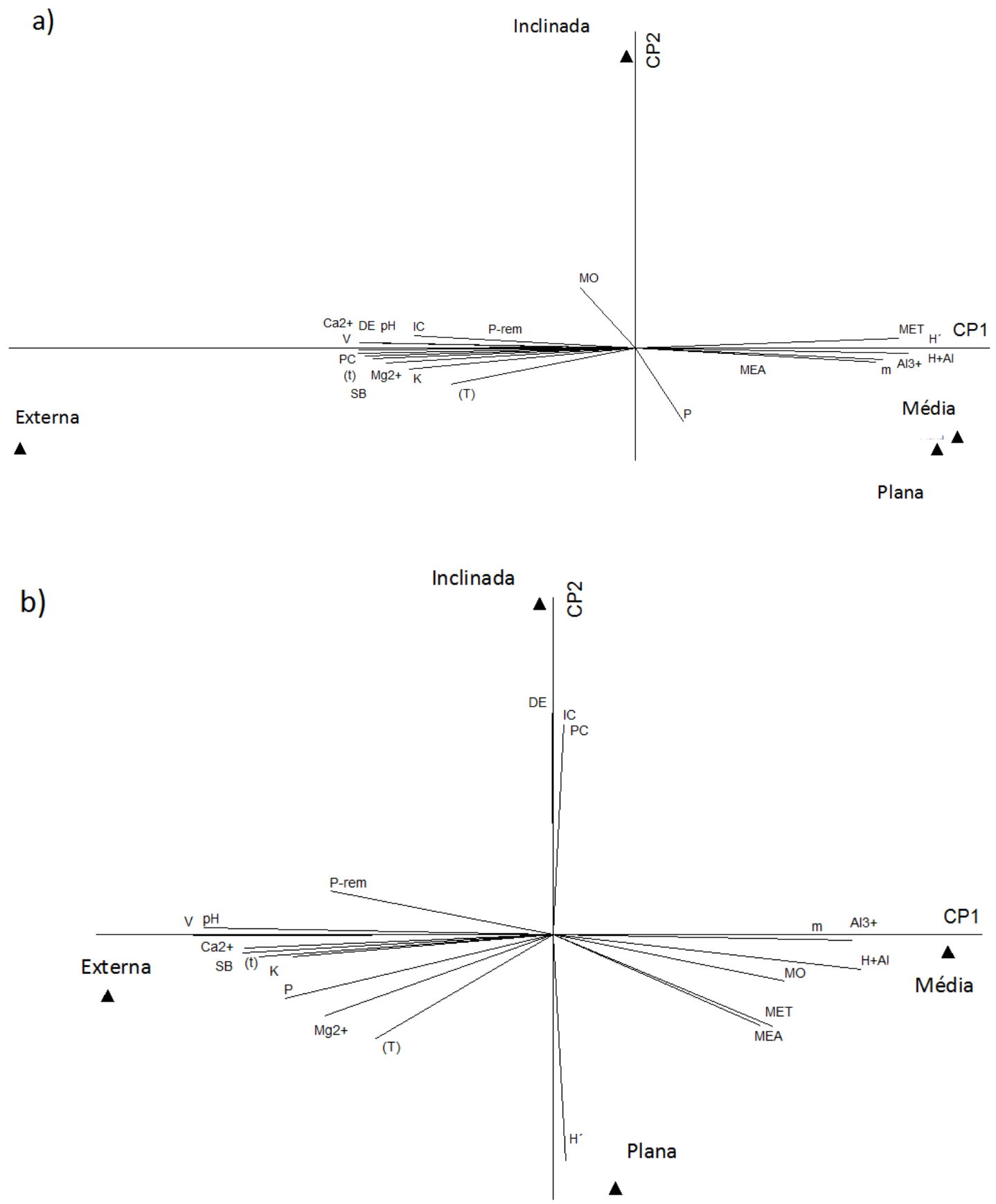

FIGURA 2: Componentes principais das médias dos atributos químicos e microbiológicos obtidos nas diferentes áreas de estudo, no inverno de 2008 (a) e verão de 2009 (b). Atributos químicos: MO (matéria orgânica), SB (soma de bases), V (saturação por bases), m (saturação por alumínio), $\mathrm{H}+\mathrm{Al}, \mathrm{T}$ (CTC a pH 7,0), t (CTC efetiva). Atributos microbiológicos: MEA (micélio extrarradicular ativo); MET (micélio extrarradicular total); IC (intensidade de colonização micorrízica); PC (porcentagem de colonização micorrízica); DE (densidade de esporos); $\mathrm{H}^{\prime}$ (índice de diversidade de Shannon-Weaver).

FIGURE 2: Principal components of chemical and microbial attributes from different areas, in winter 2008 (a) and summer 2009 (b). Chemical attributes: MO (organic matter), SB (sum of bases), V (base saturation), $\mathrm{m}$ (aluminnum saturation), $\mathrm{H}+\mathrm{Al}, \mathrm{T}$ (CTC-cation exchange capacity at pH 7,0), $\mathrm{t}$ (effective CTC). Microbial attributes: MEA (active extra-radical mycelium); MET (total extra-radical mycelium); IC (mycorrhizal colonization intensity); PC (mycorrhizal colonization percentage); DE (density of spores); H' (Shannon-Weaver index). 
nesse estudo, também observaram que ecossistemas que não recebem constante aporte externo de nutrientes (exemplo: condições naturais dentro da Reserva) apresentam propriedades químicas desfavoráveis em relação àqueles sob ação antropogênica (exemplo: fora da Reserva), sendo esses efeitos mais evidentes para o $\mathrm{C}, \mathrm{Ca}, \mathrm{K}, \mathrm{Mn}$, $\mathrm{B}$, saturação por bases, Al trocável e saturação por Al. Esses resultados confirmam a relação nem sempre direta entre fertilidade do solo e a densidade e diversidade de propágulos de fungos MAs, evidenciando a complexidade da formação dessas estruturas em função das condições climáticas e edáficas atuantes.

Portanto, houve distinção entre o potencial de inóculo (propágulos) de fungos MAs nos solos de dentro e fora da Reserva Biológica Municipal Serra dos Toledos, destacando-se a sua utilização como bioindicadores da qualidade de solos. Solos internos à Reserva apresentaram, em geral, maior comprimento de micélio extrarradicular ativo e total, enquanto que naquele externo a mesma se destacou pelos maiores índices de colonização micorrízica (intensidade e porcentagem) e tendência de maior densidade de esporos e menor diversidade fenotípica de fungos micorrízicos arbusculares. Assim, o plano de manejo dos solos da Reserva deve atentar para manter a densidade e diversidade desses micro-organismos benéficos ao desenvolvimento das plantas e à sustentabilidade desse ecossistema, atualmente sob impactos antropogênicos adversos.

\section{CONCLUSÕES}

Opotencialdeinóculode fungosmicorrízicos arbusculares, avaliado pela quantificação de micélio extrarradicular ativo e total, porcentagem e intensidade de colonização radicular, densidade e diversidade de esporos, apresenta maior efeito das áreas do que das épocas de estudo, recomendandose sua utilização como bioindicadores da qualidade em função do manejo aplicado sobre o solo.

Os atributos maior comprimento de micélio extrarradicular ativo e total, maior proporção de micélio ativo em relação ao total e maior diversidade de esporos foram obtidos nos solos dentro da Reserva Biológica Municipal Serra dos Toledos, em relação ao solo externo à mesma, sob pastagem, independentemente da época de amostragem.

O potencial de inóculo não está diretamente relacionado à fertilidade do solo, ou seja, no solo externo à Reserva, sob pastagem, apesar da melhor fertilidade, foram encontrados os menores valores de micélio e diversidade de esporos de fungos micorrízicos arbusculares.

\section{AGRADECIMENTOS}

Ao Conselho Nacional de Desenvolvimento Científico e Tecnológico $(\mathrm{CNPq})$ pelo financiamento do referido Projeto de Pesquisa.

\section{REFERÊNCIAS BIBLIOGRÁFICAS}

ALVARENGA, M. I. N. et al. C. Teor de carbono, biomassa microbiana, agregação e micorriza em solos de cerrado com diferentes usos. Ciência e Agrotecnologia, Lavras, v. 23, n. 3, p. 617-625, 1999.

BAYER, C.; MIELNICZUK, J. Dinâmica e função da matéria orgânica. In: SANTOS, G.A. et al. Fundamentos da matéria orgânica do solo Ecossistemas Tropicas \& Subtropicais. 2. ed. Porto Alegre: Metropole, 2008. cap.2, p. 7-18.

BETHLENFALVAY, G. J. et al. Measurement of mycorrhizal infection in soybeans. Soil Science of Society American Journal, Madison, v. 45, p. 871875, 1981.

BRASIL. Levantamento de recursos naturais. Folhas SF.23/24, Rio de Janeiro/Vitória; geologia, geomorfologia, pedologia, vegetação e uso potencial da terra. Rio de Janeiro: MME/SG. 780 p. / Projeto RADAMBRASIL, 1983.

CARDOSO FILHO, J. A. et al. Growth and metabolic activity of the extramatrical mycelium of endomycorrhizal maize plants. Revista Brasileira de Ciência do Solo, Viçosa, v. 23, p. 807-815, 1999. CPTEC - Centro de Previsão de Tempo e Estudos Climáticos - Plataformas de coleta de dados. Disponível em: <(satelite.cptec.inpe.br/PCD/ historico/consulta_pcdm.jsp) $>$ Acesso em: 6 de maio de 2010.

COSTA, A. Qualidade do solo, crescimento e desenvolvimento do milho sob diferentes sistemas de manejo na integração lavoura-pecuária. Dissertação (Mestrado)-Lages: Universidade do estado de Santa Catarina, 2005.

DORAN, J. W.; ZEISS, M. R. Soil health and sustainability: managing the biotic component of soil quality. Applied Soil Ecology, Amsterdam, v. 15, n. 1, p. 3-11, Jan. 2000.

EMBRAPA. Centro Nacional de Pesquisa de Solos. Manual de métodos de análise de solos. 2. ed. Rio de Janeiro: EMBRAPA-CNPS, 1997. 212 p. 
GERDEMANN, J. W.; NICOLSON, T. H. Spores of mycorrhizal endogen species extracted from soil by wet sieving and decanting. Transactions of the British Mycological Society, Cambridge, Inglaterra, v. 46, n. 2, p. 235-244, July 1963.

GIOVANETTI, M.; MOSSE, B. An evaluation of techniques for measuring vesicular arbuscular mycorrhizal infection in roots. New Phytologist, Oxford, v. 84, p. 489-500, 1980.

HEIJDEN, M. G. A. van der et al. Mycorrhizal fungal diversity determines plant biodiversity, ecosystem variability and productivity. Nature, London, v. 396, p. 69-72, Nov. 1998.

JOHNSON, N. C.; PFLEGER, F. L. Vesiculararbuscular mycorrhizae and cultural stresses. In: BETHLENFALVAY, G. J.; LINDERMAN, R. G. (Ed.). Mycorrhizae in sustainable agriculture. Madison: American Society of Agronomy, 1992. p. 71-99.

KABIR, Z. et al. Seasonal changes of arbuscular mycorrhizal fungi as affected by tillage practices and fertilization: hyphal density and mycorrhizal root colonization. Plant and Soil, The Hague, v. 192, n. 2, p. 285-293, May 1997.

KIRIACHEK, S.G. et al. Regulação do desenvolvimento de micorrizas arbusculares. Revista Brasileira de Ciência do Solo, Viçosa, v. 33, n. 1, jan./fev. 2009

KLING, M.; JAKOBSEN, I. Arbuscular mycorrhiza in soil quality assessment. Ambio, Oslo, v. 27, n. 1, p. 29-34, Feb. 1998.

McCUNE, B.; MEFFORD, M. J. Multivariate analysis of ecological data. Version 3.12. Gleneden Beach: MjM Software, 1997.

MELLONI, R. et al. Fungos micorrízicos arbusculares em solos de área de mineração de bauxita em reabilitação. Pesquisa Agropecuária Brasileira, Brasília, v. 38, n. 2, p. 267-276, fev. 2003.

MELlONI, R.; CARDOSO, E. J. B. N. Quantificação de micélio extrarradicular de fungos micorrízicos arbusculares em plantas cítricas - I: Método empregado. Revista Brasileira de Ciência do Solo, Viçosa, v. 23, n. 1, p. 53- 58, jan./mar. 1999. MELLONI, R. et al. Avaliação da qualidade de solos sob diferentes coberturas florestais e de pastagem no sul de Minas Gerais. Revista Brasileira de Ciência do Solo, Viçosa, v. 32, n. 6, p. 2461-70, nov./dez. 2008.

MELLONI, R. et al. Fósforo adicionado e fungos micorrízicos arbusculares no crescimento e nutrição mineral de limoeiro-cravo [Citrus limonia (L.)
Osbeck]. Revista Brasileira de Ciência do Solo, Viçosa, v. 24, n. 4, p. 767- 775, out./dez. 2000.

MELLONI, R. et al. Características biológicas de solos sob mata ciliar e campo cerrado no sul de Minas Gerais. Ciência e Agrotecnologia, Lavras, v. 25, n. 1, p. 7-13, jan/fev. 2001.

MELLONI, R. et al. Fungos micorrízicos arbusculares em solos de área de mineração de bauxita em reabilitação. Pesquisa Agropecuária Brasileira, Brasília, v. 38, n. 2, p. 267-276, 2003.

MIRANDA, C. C. et al. Caracterização da matéria orgânica do solo em fragmentos de mata atlântica e em plantios abandonados de eucalipto. Revista Brasileira de Ciência do Solo, Viçosa, v. 31, n. 5, set./out. 2007

MOREIRA, F. M. S.; SIQUEIRA, J. O. Microbiologia e bioquímica do solo. 2. ed. Lavras: Ed. UFLA, 2006. 729 p.

NOGUEIRA, M. A.; CARDOSO, E. J. B. N. Produção de micélio externo por fungos micorrízicos arbusculares e crescimento da soja em função doses de fósforo. Revista Brasileira de Ciência do Solo, Viçosa, v. 24, n. 2, p. 329-338, 2000.

PEREIRA, E.A.N.G. Influência do Relevo na Profundidade de Solos na Reserva Biológica Serra dos Toledos, Itajubá/MG. 2007. 142 f. Trabalho de Diploma (Engenharia Ambiental) Universidade Federal de Itajubá, Itajubá.

PEREIRA, E. G. et al. Efeito de micorrizas arbusculares e do suprimento de fósforo na resposta de espécies arbóreas ao nitrogênio mineral. Pesquisa Agropecuária Brasileira, Brasília, v. 31, n. 9, p. 653-662, 1996 b.

PEREIRA, E. G. et al. Efeito do fornecimento e formas de $\mathrm{N}$ mineral no crescimento e colonização micorrízica de mudas de espécies arbóreas nativas. Revista Brasileira de Fisiologia Vegetal, Campinas, v. 8, n. 1, p. 59-65, 1996 a.

PHILLIPS, J. M.; HAYMAN, D. S. Improved procedures for clearing roots and staining parasitic and vesicular-arbuscular mycorrhizal fungi for rapid assessment of infection. Transactions of British Mycological Society, London, v. 55, p. 158-161. 1970.

POGGIANI, F.; SCHUMACHER, M. V. Ciclagem de nutrients em florestas nativas. In: GONÇALVES, J. L. M; BENEDETTI, V. Nutrição e fertilização florestal, Piracicaba: IPEF, 2000.

POUYOU-ROJAS, E. et al. Compatibilidade simbiótica de fungos micorrízicos arbusculares com espécies arbóreas tropicais. Revista Brasileira de Ciência do Solo, Viçosa, v. 30, n. 3, maio/jun. 2006 
PREFEITURA MUNICIPAL DE ITAJUBÁ. Elaboração do Plano de Manejo: Reserva Biológica Serra dos Toledos. Itajubá, Documento apresentado ao Fundo Nacional do Meio Ambiente Edital 10/2001: Apoio à Gestão Integrada em Unidades de Conservação de Proteção Integral de Reservas Particulares do Patrimônio Natural (Administração 2001-2004), 2002.

RAMOS-ZAPATA, J.; GUADARRAMA, P. Los hongos micorrizógenos arbusculares en La restauración de comunidades tropicales. Uciencia, n. 1, p. 59-65, 2004

SHANNON, C. E.; WEAVER, W. The mathematical theory of communication. Urbana: University of Illinois, $1949.117 \mathrm{p}$.

SIQUEIRA, J. O. et al. Microorganismos e processos biológicos de solo: perspectiva ambiental. Brasília: EMBRAPA, 1994. 142 p.

SMITH, S. E.; READ, D. J. Mycorrhizal symbiosis. 2nd ed. London: Academic Press, 1997. 605 p.

SYLVIA, D.M. Quantification of external hyphae of vesicular-arbuscular mycorrhizal fungi. Methods in Microbiology, Oxford, v. 24, p. 54-65, 1992.

TURCO, R. F. et al. Microbial indicators os soil quality. In: DORAN, J. W. ... [et al.] (eds.) Defining soil quality for a sustainable environment. American Society of Agronomy, New York, v. 35, p. 73-90, 1994.

ZONTA, E. P. et al. Sistemas de análise estatística para microcomputadores (SANEST). Pelotas: UFPel - Departamento de Matemática e Estatísica, 1984. $151 \mathrm{p}$. 